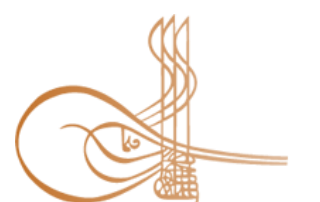

www.turkishstudies.net/economy
Turkish Studies - Economics, Finance, Politics

eISSN: $2667-5625$

Research Article / Araștırma Makalesi

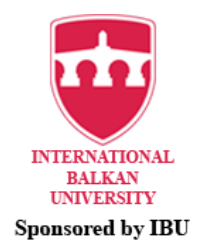

Sponsored by IBU

\title{
Elektrik Tüketimi ve Ekonomik Büyüme Arasındaki İlişkinin Bölgesel Analizi: Türkiye Örneği
}

\author{
The Regional Analys Of The Relationship Between Electricity Consumption And Economic \\ Growth: The Case of Turkey
}

\author{
Mehmet Akyol*
}

\begin{abstract}
Electricity consumption is an indicator of socioeconomic development and civilization. Developing countries as well as developed countries have increased their demand for electricity consumption in the industrialized world. In this study, the relationship between electricity consumption and economic growth were analyzed on a regional scale for Turkey. Data which are used in the study was obtain from the database of Turkish Statistical Institute. In the study, the statistical region units classification (NUTS) approach was used and 26 sub-regions called level-2 regions were included in the analysis. Firstly, whether there is a horizontal cross-section dependency between the series was tested by Pesaran test and the presence of horizontal crosssection dependence was determined. In cases of horizontal cross-section dependency, Augmented Dickey Fuller unit root test was used for determination of stationarity. As a result of the test, it was understood that the series were not stationary at the level and the first differences of the series were taken. The series became stationary in the first diffirences. In order to determine the long-term relationship between the series, the homogeneity of the series must be determined. The homogeneity of the series was tested with delta test and it was understood that the series were heterogeneous. Gengenbach, Urbain and Westerlund panel cointegration tests were used to determine the long-term relationship between the series. As a result of the analysis long term relation was determined between the series. Afterwards, long term cointegration analysis was obtained with the average group least squares estimator. According to the results of the analysis, electricity consumption has an impact on economic growth in the long run.
\end{abstract}

Structured Abstract: Energy plays an important role in realizing the growth and development efforts of today's economies. Due to the advancement of technology and the increase in the global population, the increase in global total demand encourages production and ultimately increases the need for energy. In this context, due to its ease of use, environmentally friendly structure and fast access, electrical energy is frequently preferred among energy sources. Electricity consumption has an important effect on determining the level of social development as well as economic development. In this study, the effect of electricity consumption on economic growth was analyzed on a regional scale. The regional nature of the study distinguishes the study from previous studies on the subject. In this study, the relationship between electricity consumption and economic growth were analyzed on a regional scale for Turkey. In the study, the statistical region units classification (NUTS) approach was used and 26 sub-regions which is called level-2 regions were included in

*Dr. Öğr. Üyesi, Gümüşhane Universitesi, İktisadi ve İdari Bilimler Fakültesi, İktisat Bölümü Assistant Prefessor, Gumushane University, Economics and Administrative Sciences, Department of Economics ORCID 0000-0002-1173-200X mehmet_akyol81@hotmail.com

Cite as/ Atıf: Akyol, M. (2020). Elektrik tüketimi ve ekonomik büyüme arasındaki ilişkinin bölgesel analizi: Türkiye örneği. Turkish Studies - Economy, 15(3), 1123-1139. https://dx.doi.org/10.47644/TurkishStudies.44550

Received/Geliş: 28 June/Haziran 2020

Accepted/Kabul: 20 September/Eylül 2020

Checked by plagiarism software

Copyright $(C)$ INTAC LTD, Turkey 
the analysis. In the analysis where panel cointegration test were used, the existence of a long-term cointegration relationship between electricity consumption and economic growth was determined in the period between 2005-2018. In this context, the increase in electricity consumption affects economic growth positively.

There are many studies on the subject in the literature. These studies analyzed the issue within the framework of causality. Causality analyzes are handled in 4 scopes. These are growth hypothesis, conservation hypothesis, feedback hypothesis and neutrality hypothesis. The growth hypothesis argues that there is causality from electricity consumption to gdp. The conservation hypothesis indicates the existence of one-way causality from GDP to energy consumption. The feedback hypothesis states that there is a mutual causality relationship between both variables. The neutrality hypothesis indicates that there is no mutual causality relationship between the two variables. There are many studies in the literature that analyze the relationship between energy consumption and economic growth. For example Kraft and Kraft (1978), Ghosh (2002), Quang (2011), Cowan et al. (2014), İkegami and Wang (2016), Öz and Togan (2018) and Yildirim and Dagdemir (2018) has identified a one-way relationship from gdp to electricity consumption. By the way Yoo (2006), Tang (2008), Yoo and Kwak (2010), Cowan et al. (2014), Ergun and Polat (2015) and Guvenoglu and Aydin (20189 found a mutual relationship between gdp and electricity consumption. On the other hand Das and Mcfarlane (2019), Aydin and Bozdag (2018), and Pata and Yurtkuran (2017) has identified a one way relationship from electric consumption to gdp. Finally Bah and Azam (2017, Faisal et al. (2016) concluded that there is no relationship between gdp and electricity consumption. The study differs from other studies with its regional character. The study covers the period from 2005 to 2018 and analysing in 26 sub regions in Turkey. In the study, gdp and electricity consumption data were used and the data were obtained from the Turkish Statistical Institute database.

In the study long term relationship is investigated between electric consumption and economic growth. Firstly, whether there is a horizontal cross-section dependency between the series was tested by Pesaran test. Cross section dependency test result is shown in table-1.

Table 1: Cross Section Dependence Test

\begin{tabular}{llll}
\hline Variables & CD testi & Coefficient & P value \\
LKBGSYH/LTET & 56.65 & 0.840 & $0.000 *$ \\
\hline
\end{tabular}

Analysis results shows that the presence of horizontal cross-section dependence was determined between series. In cases of horizontal cross-section dependency, Augmented Dickey Fuller unit root test was used for determination of stationarity.

Table 2: Unit Root Test Results

\begin{tabular}{|c|c|c|c|c|c|c|}
\hline \multicolumn{7}{|c|}{ I(0) Level Value } \\
\hline Variables & t-bar & cv10 & cv5 & $\mathrm{cv} 1$ & $\mathrm{Z}(\mathrm{t}-\mathrm{bar})$ & $\mathrm{P}$ value \\
\hline LKBGSYH & -2.024 & -2.070 & -2.170 & -2.340 & -1.408 & $0.080 * * *$ \\
\hline LTET & -2.024 & -2.070 & -2.170 & -2.340 & -1.407 & $0.080 * * *$ \\
\hline \multicolumn{7}{|c|}{ I(1) First Diffirences Value } \\
\hline LKBGSYH & -2.691 & -2.070 & -2.170 & -2.340 & -4.502 & $0.000 *$ \\
\hline LTET & -3.303 & -2.070 & -2.170 & -2.340 & -7.338 & $0.000 *$ \\
\hline
\end{tabular}

As a result of the test, it was understood that the series were not stationary at the level and the first differences of the series were taken. The series became stationary in the first diffirences. In order to determine the long-term relationship between the series, the homogeneity of the series must be determined. When the results of table- 2 are evaluated, it was understood that the series were not stationary at the level and the first differences of the series were taken. Homogenity test is shown in table-3. 
Table 3: Homogenity Test

\begin{tabular}{lll}
\hline Delta Test & Statistics & P value \\
$\Delta$ & 2.076 & $0.038^{* *}$ \\
\hline
\end{tabular}

The delta test results show that the series are not homogeneous. Gengenbach, Urbain and Westerlund panel cointegration tests were used to determine the long-term relationship between the series. Table- 4 shows that there is a long term relationship was determined between the series.

Table 4: Panel Cointegration Test

\begin{tabular}{llll}
\hline d.y & Coefficient & T Statistics & value \\
$\mathrm{y}(\mathrm{t}-1)$ & $-1.054^{*}$ & -2.809 & $<0.01$ \\
\hline Long-Term Relations: Average Group Least Squares Estimation (DOLSMG) & \\
\hline LKBGSYH & Beta Coefficient & T Statistics & \\
\hline LTET & 0.139 & 5.262 & \\
\hline
\end{tabular}

In table-4 The beta coefficient indicates the long-term parameter estimate. On the other hand, Longterm $t$ statistics are significant. According to the DOLSMG results, the LTET independent variable affects the LKBGSYH dependent variable in the long run. The 1 point increase in the percentage change of total electricity consumption increases the percentage change in GDP per capita by 0.14 points. In the last part of the econometric research, the panel expanded average group (AMG) estimator is used to estimate cointegration coefficients in the presence of inter-unit correlation and heterogeneity. Results are shown in table-5.

Table 5: Long Run Cointegration Coefficint Result

\begin{tabular}{llcc}
\hline LKBGSYH & Coefficient & T statistics & P value \\
LTET & $0.275^{*}$ & 4.04 & 0.000 \\
\hline Other Statistics on Cointegration Test & & \\
\hline Error Correction Parameter & -1.84 & -50.56 & 0.000 \\
Wald test Statitstics & & 9375.03 & \\
Wald p değeri & & 0.000 \\
\hline
\end{tabular}

Table-5 provides an estimate of the error correction model using the AMG estimator for the overall panel. Considering the results, the increase in electricity consumption in these regions affects the gross domestic product per capita positively and statistically significantly. The error correction coefficient was found as -1.84 in the model and it is statistically significant at the level of $1 \%$. As a result, an unexpected shock effect that will emerge in the short term, will be corrected by $1.84 \%$ every year in the long term.

The long-term positive effect of electricity consumption on economic growth increases the importance of the policies. Turkey is dependent on foreign energy and this dependency is increasing energy costs. Although the increase in costs will bring the reduction in electricity consumption to the agenda, the reduction in electricity consumption will have negative socioeconomic effects. In this context, it is important to redesign policies for electricity consumption. Additional measures to be taken to prevent losses and illicit use that may occur during the electricity transmission process. It is essential to develop alternative energy systems in order to reduce the dependence on non-renewable sources in electricity supply. Therefore, the promotion of renewable energy investments to be made by the public and private sector plays a major role in the production of electricity. Besides, it is important to take political steps to develop domestic production technologies.

Keywords: Economic Growth, Energy Consumption, Panel Time Series Analysis,

Öz: Elektrik tüketimi, sosyoekonomik gelişmişliğin ve uygarlığın bir göstergesi niteliğindedir. Sanayileşmenin hız kazandığı günümüzde gelişmiş ülkeler kadar gelişmekte olan ülkeler de elektrik tüketimine olan taleplerini 
arttırmıştır. Bu çalışmada elektrik tüketimi ile ekonomik büyüme arasındaki ilişki Türkiye için bölgesel ölçekte analiz edilmiştir. Araştırmada kullanılan veriler Türkiye İstatistik Kurumu veri tabanından elde edilmiştir. Araştırmada istatistiksel bölge birimleri sınıflandırma (İBBS) yaklaşımı kullanılmış ve düzey-2 olarak adlandırılan 26 alt bölge analize dahil edilmiştir. İlk olarak, seriler arasında yatay kesit bağımlılığının olup olmadığı Pesaran testi ile test edilmiş ve yatay kesit bağımlılığının varlığı belirlenmiştir. Yatay kesit bağımlılığı durumunda durağanlığın belirlenmesi için Genişletilmiş Dickey Fuller birim kök testi kullanılmıştır. Test sonucunda serinin düzeyde durağan olmadığı anlaşılmış ve birinci farkları alınmış ve seriler birinci farkında durağan olmuştur. Sonrasında seriler arasındaki uzun vadeli ilişkiyi belirlemek için serilerin homojenliği delta testi ile test edilmiş ve serilerin heterojen olduğu anlaşılmıştır. Seriler arasındaki uzun vadeli ilişkiyi belirlemek için yatay kesit bağımlılı̆̆ ve heterojenlik durumunda uygun olan Gengenbach, Urbain ve Westerlund panel eşbütünleşme testleri kullanılmıştır. Analiz sonucunda seriler arasında uzun süreli bir ilişki olduğu belirlenmiştir. Daha sonra ortalama grup en küçük kareler tahmincisi ile uzun dönem eşbütünleşme analizi elde edildi. Analiz sonuçlarına göre, elektrik tüketiminin uzun vadede ekonomik büyüme üzerinde etkisi olduğu sonucuna ulaşılmıştır.

Anahtar Kelimeler: Ekonomik Büyüme, Elektrik Tüketimi, Panel Zaman Serileri Analizi,

\section{Giriş}

Son yüzyılda sanayi üretiminin hız kazanması ve teknolojik ilerlemeler enerji tüketimini hızlandırmıştır (Hirsh \& Koomey,2015:72). Özellikle sanayi üretiminde enerjinin payının artması enerji kullanımının sürekliliğini gündeme getirmiş ve enerjiye olan bağımlılığ da arttırmıştır (Adeniyi \& Adewuyi,2019). Üretim süreçlerinde temel girdi olan enerji aynı zamanda sürdürülebilir kalkınmanın sağlanmasında da ön şarttır (Dudzevıčıūtė \& Šımelyte,2017:396). Nitekim petrol ve doğalgaz gibi yenilenemez enerji rezervlerinin her geçen gün azalıyor olması sürdürülebilir kalkınma ve ekonomik büyümenin önünde engel teşkil etmektedir. Sürdürülebilir kalkınmanın ve ekonomik büyümenin kaynağı olarak görülen enerji bu özellikleriyle stratejik bir öneme sahiptir. 1970'li yıllarda yaşanan petrol krizi, 1990 ve 2008 yıllarında enerji fiyatlarında küresel ölçekte gözlemlenen aşırı artış eğilimi, enerjinin ülkeler için ne kadar önemli olduğunu gözler önüne sermiştir (Bayar \& Özel,2014:1). Gerek reel sektörde gerekse kamusal alanda enerjiye olan ihtiyacın her geçen gün katlanarak artması enerji kaynaklarına sahip olmayı gerekli kılmaktadır. Diğer yandan önemli bir üretim girdisi olan enerjinin üretim maliyetlerinin belirlenmesinde rol oynaması uluslararası rekabet şartlarının ağırlaştığı günümüz iktisadi yaşantısında enerji kaynaklarına sahip olmanın önemini bir kere daha vurgulamaktadır.

Enerji tüketiminin artış hızı özel sektör iş çevrelerini ve kamu politikalarını kayda değer oranda etkilemektedir. Enerji tüketimine yönelik talep artışı hiç şüphesiz sektörde faaliyette bulunan üreticiler için gelir kaynağı oluşturmakta ve sektörel büyümeye katkı sağlamaktadır. Fakat artan ihtiyacın karşılanması için geleneksel üretim yöntemlerine sıklıkla başvurulması kirliliğin yanısıra çevresel sorunları da beraberinde getirmektedir (Hirsh \& Koomey,2015:72). Nitekim 2019 yıl1 verilerine göre enerji tüketimindeki artışa bağlı olarak karbondioksit emisyonu \%1-1.5 oranında artış göstermiştir. (Enerdata,2019).

Enerji kaynakları birincil ve ikincil kaynaklar olarak ayrılmaktadır. Ham petrol, doğal gaz, kömür uranyum (nükleer yakıt olarak) vb. gibi yenilenemeyen rezervler içerisinde yer alan enerji kaynakları ile güneş, rüzgar ve dalga gibi yenilenebilir rezervler içerisinde yer alan kaynaklar birincil enerji kaynaklarını oluşturmaktadır. İkincil enerji kaynakları ise birincil kaynakların dönüşüme uğratılması neticesinde elde edilen petrole dayalı ürünler, biyo gazlar ve elektrik gibi enerji kaynaklarından oluşmaktadır (Overgaard,2008). 2017 yılında küresel ölçekte \%1.8 artan birincil enerji tüketimi 2010-2018 yılları arasında ise ortalama \%1.3 artış sergilemiştir. 2018 yılı verilerine göre ise dünya genelinde toplam birincil enerji tüketimi \%2.1 oranında artmıştır. Bu haliyle enerji tüketimi küresel krizden bugüne kadar geçen 9 yıllık sürede aralıksız artışını sürdürmüștür. OECD ülkelerinde tüketim \%1 artarken özellikle Rusya, Çin ve Hindistan'ın başı çektiği OECD dışındaki 
ülkelerde ise tüketim \%3 oranında artmıştır (Enerdata,2019). Bu durumun geri planında gelişmiş ve gelişmekte olan ülkelerin enerji ihtiyaçlarının farklı nedenlere dayanması yatmaktadır. Gelişmiş ülkeler genellikle sanayi sektörünü canlı tutmak adına enerjiye ihtiyaç duyarken gelişmekte olan ülkeler ise gelişmiş ülke statüsüne sahip olmak ve gelişmiş ülkelere yakınsamak adına enerji talebinde bulunmaktadır (Atif \& Siddigi,2010).

Enerji kaynakları içerisinde elektrik enerjisi farklı bir konuma sahiptir. Enerjinin esnek bir formu olan elektrik enerjisi aynı zamanda sosyo-ekonomik kalkınma için gerekli olan üretim girdilerinin de altyapısını oluşturmaktadır (Ghosh,2002:125). Elektrik enerjisi diğer enerji kaynaklarına göre çeşitli avantajları bünyesinde barındırmaktadır. $\mathrm{Bu}$ avantajlar arasında bütün birincil kaynaklardan elde edilebilmesi, kullanımının kolay olması ve diğer enerji kaynaklarına dönüştürülebilmesi gösterilebilir (Güvenoğlu \& Aydın,2018:622). Diğer yandan zararlı sera gazı etkilerinin azaltılarak çevreci bir görünüm sergilemesi, üretim maliyetinin görece düşük olması ve kısmen depolanabilir olma özelliği elektrik enerjisinin diğer avantajlarını oluşturmaktadır.

Gelişmekte olan ülkelerin iktisadi olarak büyüme ve gelişmiş ülkelere yakınsama çabası söz konusu ülkelerin enerjiye olan gereksinimlerini de arttırmaktadır. Nitekim dünya nüfusunun büyük bir kısmını oluşturan ve gelişmekte olan ülkeler grubunda yer alan BRICS ülkelerinde 2010-2018 yılları arasında elektrik enerjisi tüketimi artış oranı \%70 düzeylerindedir. Elektrik tüketiminde en hızlı artış ise \%80 oranıyla Asya'da gözlenmiştir. Bu artışa en büyük katkıyı Çin yapmıştır. Diğer yandan Avrupa'da ise elektrik tüketimi 2017 yılında olduğu gibi 2018 yılında da durağan seyretmiştir (Enerdata,2019).

Elektrik enerjisi ikincil enerji kaynağı olmasının yanısıra yenilenemez rezervler olan ham petrol, doğalgaz ve kömür gibi kaynaklar ile rüzgar, dalga ve güneş gibi yenilenebilir kaynaklardan da sağlanmaktadır. Elektrik enerjisi üretiminde geleneksel yöntem olan kömür rezervlerinden sıklıkla yararlanılmaktadır. Son zamanlarda ise nükleer santraller ve doğal gaz kaynakları petrolün aksine elektrik üretiminde başvurulan kaynaklardan olmuştur. 1970 petrol krizi sonrasında petrol fiyatlarında meydana gelen artışlar elektrik üretiminde petrolün kullanımını azaltmıştır (Bayar \& Özel,2014:2).

Elektrik enerjisi üretim süreci gelişmiş ülkelerde gelişmekte olan ülkelere nazaran çok daha karmaşıktır. Bu bağlamda gelişmiş ülkelerde enerji üretimi biokütle dahil birçok alternatif enerji kaynaklarına dayanmakta iken gelişmekte olan ülkeler ise daha çok geleneksel kaynaklardan elektrik enerjisi elde etme yoluna gitmekte ve henüz kömür, hidroelektrik enerji ve doğal gaz gibi temel elektrik arzı kaynaklarını verimli bir şekilde kullanamamaktadır. (Atif \& Siddigi,2010). Elektrik enerjisi farklı teknolojilere rahatlıkla uygulanabilmesi, geleneksel ve yeni nesil olmak üzere çeşitli enerji kaynaklarından elde edilebilmesi, diğer enerji kaynaklarına nazaran kullanım kolaylığı ve güvenliği sağlaması gibi olumlu yönleriyle üretim sürecinde sıklıkla başvurulan önemli bir enerji kaynağıdır (Yapraklı \& Yurttançıkmaz,2012:196).

Elektrik enerjisi kullanımının pozitif özellikleri talep artışını da beraberinde getirmektedir. Bu bağlamda politik senaryolara göre küresel ölçekte elektrik talebinin 2040 yılına kadar yıllık \%2.1 oranında artması beklenmektedir. $\mathrm{Bu}$ haliyle elektrik talebi, birincil enerji talebini ikiye katlamaktadır. 2018 yılında toplam enerji tüketimi içerisinde elektrik tüketiminin pay1 \%19 iken 2040 yılına gelindiğinde bu oranın \%24 seviyesine çıkması beklenmektedir. Günümüzde elektrik arzının \%36'lık kısmı karbon salınımının daha düşük olduğu kaynaklardan sağlanırken hükümetler tarafından geliştirilen politikalar, piyasa şartları ve teknolojide meydana gelen ilerlemeler neticesinde, bu oranın 2040 yılında \%52 düzeylerine çıkması öngörülmektedir (IEA,2019). Başta sanayi sektörü olmak üzere çok geniş bir alanda kullanılan elektrik enerjisi aynı zamanda üretimin verimliliğini de etkilemektedir. Elektrik enerjisi sanayileşmeye ivme kazandırarak ihracata olumlu katk1 sağlamakta ve toplumsal refahı arttırmaktadır (Türkmen vd.,2018). Elektrik tüketimi bu yönüyle ekonomik büyümeyi de olumlu yönde etkilemektedir. Elektrik tüketiminin ekonomik 
büyüme üzerindeki etkisi sermaye, emek ve teknik kapasitenin geliştirilmesi yoluyla gerçekleşmektedir. Elektrik tüketimi iktisadi refah oluşturmanın ötesinde sosyoekonomik gelişmişlik düzeyini de belirleyen önemli bir faktördür (Shengfeng vd.,2012:56).

Gelişmekte olan diğer ülkeler gibi Türkiye'de de elektrik enerjisine olan talep ve elektrik tüketimi artmaktadır. Talep artışında hiç şüphesiz nüfus artışı, sektörel gelişmeler ve küresel değişimler etkili olmaktadır. 1971-2016 yılları arasında Türkiye'nin kişi başı elektrik tüketimi birkaç kriz dönemi hariç sürekli artış eğilimi sergilemiştir. Ekonomide meydana gelen iyileşmeler ve kişi başına düşen GSYH artışları elektrik tüketimine olan talebi pozitif yönde etkilemiştir (Karagöl \& Tür,2017:10). Nitekim 2018 yılında elektrik tüketimi 2017 yılına göre $\% 2.2$ düzeyinde artış sergilemiştir. 2023 yılı projeksiyonuna göre elektrik tüketiminin her yıl ortalama $\% 4.8$ oranında artacağı öngörülmektedir. (ETKB,2020).

$\mathrm{Bu}$ çalışmada ikincil enerji kaynağı olan elektrik enerjisinin ekonomik büyüme üzerindeki etkisi analiz edilmiştir. Çalışmanın ilk bölümünde elektrik tüketimi ve ekonomik büyüme arasındaki ilişkiyi incelemek adına önceki çalışmalar gözden geçirilmiş ve literatüre yer verilmiştir. İkinci bölümde çalışmada kullanılan veri seti ve ekonometrik analiz yöntemine değinilmiştir. Üçüncü bölümde analiz neticesinde ortaya konulan bulgular yorumlanmıştır. Çalışmanın sonuç kısmında ekonometrik analiz bulguları doğrultusunda politika önerilerine yer verilmiştir.

\section{Literatür Özeti}

Enerji ekonomisi çalışmalarında genellikle enerji tüketimi ve ekonomik büyüme arasındaki ilişki nedensellik analizi ile ortaya konulmaya çalışılmaktadır. Nedensellik analizlerinden ilki büyüme hipotezi olarak adlandırılmakta ve elektrik tüketiminden GSYH'ya doğru tek yönlü bir nedensellikten bahsetmekte ve çıktının enerji tüketimine bağlı olduğunu ifade etmektedir. İkincisi koruma hipotezi olarak adlandırılmakta ve GSYH'dan enerji tüketimine doğru tek yönlü nedenselliğin varlığını belirtmekte, enerji tüketiminin çıtıya bağlı olduğunu ifade etmekte ve enerji kullanımında meydana gelen azalmanın GSYH üzerinde olumsuz bir etki yapmayacağını vurgulamaktadır. Geri bildirim hipotezi olarak adlandırılan üçüncü durumda ise her iki değişken arasında karşılıklı nedensellik ilişkisi mevcuttur. Dördüncü ve son olarak tarafsızlık hipotezi ise iki değişken arasında karşılıklı nedensellik ilişkisinin olmadığını ve değişkenlerin birbirini etkilemediğini belirtmektedir (İkegami \& Wang,2016:768). Elektrik tüketimi ve ekonomik büyüme arasındaki nedensellik ilişkisinin yönü politika belirlenmesi sürecinde etkili olmaktadır. Şöyle ki elektrik tüketiminden ekonomik büyümeye doğru tek yönlü nedensel ilişkinin varlığı elektrik tüketiminin azalması neticesinde ekonomik büyümenin de azalacağını ifade etmektedir. Diğer yandan ekonomik büyümenin elektrik tüketiminin nedeni olması elektrik tüketiminin azaltılmasına dair alınacak politik kararların ekonomik büyüme üzerinde olumsuz bir etki oluşturmayacağını göstermektedir (Yoo \& Kwak,2010:182). Bu kapsamda enerji tüketimi ve ekonomik büyüme arasındaki iliş̧inin net bir şekilde anlaşılması etkin enerji ve çevresel politikaların geliştirilmesinde önemli bir rol oynamaktadır (Adhikari \& Chen,2012:68).

Literatürde enerji tüketimi ve ekonomik büyüme arasındaki ilişkiyi analiz eden birçok çalışma vardır. Bu çalışmalardan ilki Kraft ve Kraft (1978) tarafından kaleme alınmıştır. Çalışma enerji ve ekonomik büyüme arasındaki ilişkiyi analiz eden temel çalışmalardan biridir ve bu alanda yol gösterici niteliğe sahiptir. Çalışma sonucunda elde edilen bulgular milli gelirden toplam enerji girdisine doğru nedensel bir ilişkinin varlığını desteklerken enerji girdisinden milli gelire doğru nedensel bir ilişki gözlenmediğini ortaya koymuştur. Ayrıca ekonomik aktivitelerin enerji tüketimi üzerinde olumlu etkileri olduğu sonucuna ulaşılmıştır. Elektrik enerjisinin kullanımının yaygınlaşması ve ekonomik aktivitelerdeki hızlı gelişme iktisat yazınında enerjinin bir alt bileşeni olan elektrik enerjisi ile ekonomik büyüme ilişkisini inceleyen yeni çalışmaların literatüre eklenmesine yardımcı olmuştur. Bu bağlamda Ghosh (2002)'un çalışması dikkat çekmektedir. 19501997 yılları arası dönemde Hindistan'da kişi başına düşen elektrik tüketiminin GSYH üzerindeki 
etkisinin analiz edildiği çalışmada ekonomik büyümeden elektrik tüketimine doğru nedensel bir ilişki tespit edilmiştir. Sonuçlara göre gelirde meydana gelen artışlar elektrik tüketiminin artmasında rol oynayan önemli bir faktördür. Ferguson vd. (2000), elektrik tüketimi ve ekonomik kalkınma arasındaki ilişkiyi 100 ülke temelinde değerlendirmiştir. Analiz sonuçlarına göre elektrik tüketimi ve refah düzeyi arasında güçlü bir korelasyon ilişkisi tespit edilmiştir. Bah ve Azam (2017) elektrik tüketimi, ekonomik büyüme, finansal kalkınma ve karbondioksit emilimi arasındaki ilişkiyi Güney Afrika için test etmiştir. 1971-2012 yıllarını kapsayan dönemin test edildi çalışmadan elde edilen sonuçlar elektrik tüketimi ve ekonomik büyüme arasında herhangi bir nedensel ilişkinin var olmadığını, finansal kalkınma ile karbondioksit emisyonu arasında ise karşılıklı nedensel ilişkinin varlığını ortaya koymuştur. Ikegami ve Wang (2016) elektrik tüketimi ve büyüme arasındaki ilişkiyi Almanya ve Japonya özelinde ele almıştır. 1996-2015 yıllarını kapsayan çalışmada elektrik tüketimi ve büyüme arasında her iki ülkede uzun dönemli ilişkinin varlığı tespit edilmiştir. Her iki ülke için yapılan nedensellik analizlerinde ise Japonya'da elektrik tüketiminden GSYH'ya doğru nedensellik mevcut iken Almanya'da ise tersi sonuç vermiş ve elektrik tüketimi GSYH'daki dalgalanmalardan etkilenmişstir.

Faisal vd.(2016) Rusya ekonomisi özelinde yaptıkları çalışmada 1990-2011 y1lları arasında elektrik tüketimi ve ekonomik büyüme arasında ilişkinin varlığını tespit etmiştir. Çalışmadan elde edilen diğer bir bulgu elektrik tüketimin ekonomik büyüme üzerinde belirleyici bir etkisinin olmadığıdır. Rusya hükümetinin enerjiye erişimi ve daha yüksek düzeylerde tüketimi teşvik etmeye yönelik politikalar geliştirmesi ekonomik büyümeye olumlu bir etki yapmamıştır. Tang (2008) ekonomik büyüme ve elektrik tüketimi ilişkisini Malezya özelinde test etmiştir. 1972-2003 yıllarını kapsayan çalışmada iki değişken arasında eşbütünleşme ilişkisine rastlanmamış fakat karşıllklı nedensel ilişki tespit edilmiştir. Cowan vd. (2014) BRICS ülkeleri için yaptıkları analizde 1990-2010 yılları arası dönemde elektrik tüketimi, karbondioksit emisyonu ve ekonomik büyüme ilişkisini test etmiştir. Test sonuçları Brezilya, Hindistan ve Çin'de iki değişken arasında nedensellik ilişkisi olmadığı sonucuna varılırken Rusya'da karşılıklı nedensellik, Güney Afrika'da ise ekonomik büyümeden elektrik tüketimine doğru nedensellik olduğu anlaşılmıştır. Yoo (2006) ASEAN ülke grubu için ele aldığ 1 çalışmada 1971-2002 yılları arasında elektrik tüketimi ve ekonomik büyüme arasındaki ilişkiyi analiz etmiş̧ir. Elde edilen sonuçlara göre Singapur ve Malezya'da elektrik tüketimi ve ekonomik büyüme arasında karşılıklı nedensel ilişkiye rastlanmış, Endonezya ve Tayland'da ise elektrik tüketiminden ekonomik büyümeye doğru tek yönlü nedensel ilişkinin varlığ 1 kanıtlanmıştır. Das ve Mcfarlane (2019) elektrik tüketimi, elektrik enerjisi kayıpları ve ekonomik büyüme arasındaki ilişkiyi Jamaika için 1971-2014 yılları arası dönem için analiz etmiştir. Analiz sonucunda uzun dönemde elektrik enerji kayıplarında meydana gelen pozitif bir şok (elektrik kayıplarının azaltılması) GSYH üzerinde pozitif bir etki oluşturmakta, elektrik tüketimi ise GSYH'y1 arttırmaktadır. Diğer yandan enerjiyi oluşturan değişkenlerde meydana gelen artıştan GSYH'ya doğru nedensel bir iliş̧ki söz konusudur. Quang (2011), Vietnam'da elektrik tüketimi ve ekonomik büyüme arasındaki ilişkiyi 1975-2010 yılları için incelemiş ve GSYH'dan kişi başı elektrik tüketimine doğru tek yönlü nedensellik ilişkisi olduğu sonucuna ulaşmıştır. Yine Tang vd. (2016) enerji tüketimi ve ekonomik büyüme arasındaki ilişkiyi Vietnam özelinde 1971-2011 arası dönemi esas alarak analiz etmiştir. Çalışma sonucunda enerji tüketimi, doğrudan yabancı yatırımlar ve sermaye stoklarının Vietnam ekonomisine olumlu etki ettiği ve büyümeyi arttırdığını göstermiştir. Granger nedensellik testi sonuçları Vietnam'da enerji tüketiminden ekonomik büyümeye doğru tek yönlü bir ilişkinin varlığını ispatlamıştır. Yoo ve Kwak (2010), Güney Amerika'nın 7 ülkesinde ekonomik büyüme üzerinde elektrik tüketimim etkisinin olup olmadığını sorguladığı çalışmada 1975-2006 yılları arası dönemi analiz etmiştir. Analiz sonucunda Arjantin, Brezilya, Şili, Kolombiya ve Ekvator'da kısa dönemde elektrik tüketiminde meydana gelen artışın ekonomik büyümeyi etkilediği sonucuna ulaşmıştır. Venezuela' da değişkenler arasında iki yönlü ilişki bulunmuş, Peru'da ise herhangi bir ilişki tespit edilmemiştir. Osman vd. (2016), Körfez Birliği ülkelerine yönelik yaptıkları ve elektrik tüketiminin ekonomik büyüme üzerindeki etkisini analiz ettikleri çalışmada 
1975-2012 yılları arasında her iki değişkenin uzun dönemde karşılıklı nedensel ilişki içerisinde olduklarını gözlemlemiştir. Ergün ve Polat (2015), tarafından OECD ülkelerinde 1980-2010 yılları arasında karbondioksit emisyonu, elektrik tüketimi ve ekonomik büyüme arasındaki ilişkinin varlığ analiz edilmiştir. Eşbütünleşme analizi sonucunda 30 OECD ülkesinde söz konusu üç değişken arasında eşbütünleşme ilişkisi olduğu gözlenmiştir. Uzun dönemde 30 OECD ülkesinin bir çoğunda elektrik tüketimi ve karbondioksit emisyonu arasında istatistiksel olarak anlamlı ilişkinin varlığ tespit edilmiştir. Son olarak söz konusu ülke grubunda kısa dönemde GSYH ile karbondioksit emisyonu arasında tek yönlü nedensellik ilişkisi, GSYH ile elektrik tüketimi arasında ise karşılıklı nedensellik ilişkisi olduğu analiz sonuçlarından elde edilen diğer bulgulardır.

Güvenoğlu ve Aydın (2018), elektrik tüketimi ve ekonomik büyüme ilişkisini Türkiye'de iller bazında analiz etmiştir. 2007-2014 yıllarını kapsayan çalışmada iki değişken arasında karşılıklı nedensellik ilişkisi tespit edilmiştir. Öz ve Togay (2018), Türkiye'de elektrik sektöründe ortaya konan yapısal reformların ekonomik büyüme üzerindeki etkilerini 1980-2015 arası dönem için analiz ettiği çalışmada iki değişken arasında eşbütünleşik ve uzun dönemli bir ilişkinin varlığını ispat etmiştir. Sonrasında yapılan nedensellik testi sonuçlarına göre GSYH'dan elektrik tüketimine doğru nedensel ilişkinin varlığı doğrulanmıştır. Pata ve Yurtkuran (2017), aralarında Türkiye, ABD, Belçika, İngiltere ve İspanya'nın bulunduğu 5 ülkede elektrik tüketimi ve ekonomik büyüme arasındaki ilişkiyi nedensellik çerçevesinde incelemiştir. 1964-2014 yılları arası dönem için yapılan analizde kısa ve uzun dönemde elektrik tüketiminden ekonomik büyümeye doğru tek yönlü nedensellik ilişkisi saptanmıştır. Aydın ve Bozdağ (2018), Avrupa Birliği için 1960-2014, Türkiye için ise 1977-2014 y1llarını kapsayan dönemde elektrik tüketimin ekonomik büyümeye etkisini test etmiştir. Çalışma sonucunda elde edilen bulgular, her iki örneklemde değişkenler arasında eşbütünleşme ilişkisinin olduğunu ortaya koymuştur. Diğer yandan $A B$ ve Türkiye için elektrik tüketiminden ekonomik büyümeye doğru tek yönlü bir nedensellik ilişkisine de ulaşılmıştır. Yıldırım ve Dağdemir (2018), Türkiye'de 1999-2015 yılları arasında elektrik tüketimi ve ekonomik büyüme ilişkisini analiz etmiş ve elektrik tüketiminden GSYH'ya doğru tek yönlü nedensel ilişki tespit edilmiştir.

\section{Veri Seti ve Yöntem}

Bu çalışmada enerji tüketimi ve ekonomik büyüme arasındaki eşbütünleşme ilişkisi bölgesel olarak analiz edilmektedir. Çalışmanın bağımlı değişkenini kişi başına düşen GSYH'da meydana gelen değişim oranları (KBGSYH) oluştururken bağımsız değişkeni ise toplam elektrik tüketiminde meydana gelen değişim oranı (TET) oluşturmaktadır. Çalışmada kullanılan veriler Türkiye istatistik Kurumu (TUIK) veri tabanından elde edilmiş ve verilerin doğal logaritmaları alınmıştır.

Enerji tüketimi ve ekonomik büyüme arasındaki ilişkinin bölgesel analizinde AB tarafindan geliştirilen istatistiki bölge birimleri (IBB) sınıflandırmasına göre sosyoekonomik gelişmişlik endeksi (SEGE) sıralamasından yararlanılmaktadır. Söz konusu sıralamada sosyal ve iktisadi alanlardan seçilen 58 değişkenden hareket edilmektedir. Değişkenlerin bileşik endeksleri oluşturularak bu endeksten elde edilen değerlere göre iller ve bölgeler için gelişmişlik düzeyleri belirlenmekte ve belirlenen düzeylere göre sıralaması yapılmaktadır. SEGE sonuçları bölgeler arası gelir farklılıklarının tespiti, farklı sosyoekonomik gelişmişlik düzeyine sahip bölgelerin karşılaştırılması, kalkınmada öncelikli yörelerin belirlenmesi, kamu kaynaklarının ve özel sektör teşviklerinin bu yörelere yönlendirilmesinde kilit rol oynamaktadır. Bu haliyle SEGE verileri ekonomik gelişmişliğin çok ötesinde toplumsal yapıyı göz önünde bulundurarak bölgesel insani gelişmişlik düzeyini yansıtmaktadır (Özaslan,2015:184-185).

Modelde kullanılacak denklem aşağıdaki eşitlikte gösterilmektedir.

$L K B G S Y H_{i t}=\alpha_{i t}+\beta_{1} L T E T_{i t}+u_{i t}$ 
Ekonometrik analizlerde elde edilen sonuçların güvenirliğini etkileyen önemli bir faktör serilerin durağanlığıdır. Ekonometrik analizlerde kullanılan serilerin durağan olmaması sahte regresyon sonucu ile karşılaşılmasına neden olmaktadır. Analizde yer verilen serilerin durağanlığı birim kök testleri ile sınanmaktadır. Panel veri ekonometrisinde serilerin durağanlığını analiz ederken kullanılan birim kök testleri birinci kuşak ve ikinci kuşak testler olarak ikiye ayrılmaktadır. Serilerde yatay kesit bağımlılığının olmadığı, yani birimlerarası korelasyona rastlanmadığı durumlarda birinci kuşak birim kök testleri kullanılırken serilerde yatay kesit bağımlılığının yani birimler arasında korelasyonun olduğu durumda ise ikinci kuşak birim kök testleri kullanılmaktadır (Tatoğlu Yerdelen, 2013). Serilerin durağan olup olmadığının tespiti için hangi birim kök testinin kullanılacağının seçiminde yatay kesit bağımlılı̆̆ının sınanması gerekmektedir. $\mathrm{N}>\mathrm{T}$ olduğu durumlarda Pesaran tarafindan geliştirilen CD birimler arası korelasyon testi kullanılmaktadır. Pesaran CD testinde her bir birimin kendisi dışındaki tüm birimlerle korelasyonu hesaplanmaktadır. $\mathrm{N}$ birim boyutu iken $\mathrm{N}^{*} \mathrm{~N}-1$ ifadesi hesaplanan korelasyon miktarını göstermektedir ( Tatoğlu Yerdelen,2017:105). Bu bağlamda hipotezler:

$\mathrm{H}_{0}: \mathrm{p}_{\mathrm{ij}}=0$ ve $\mathrm{H}_{1}: \mathrm{p}_{\mathrm{ij}} \neq 0$

şeklinde kurulmaktadır. Hipotezlerde yer verilen $\mathrm{p}_{\mathrm{ij}}$ : i j birimlerin kalıntıları arasındaki korelasyon katsayısını ifade etmektedir. Pesaran'ın birimler arası korelasyonun sınanmasında dengeli panel için geliştirdiği test istatistiği;

$\mathrm{CD}=\sqrt{\left(\frac{2 \mathrm{~T}}{\mathrm{~N}(\mathrm{~N}-1)}\right)}\left\{\sum_{\mathrm{i}=1}^{\mathrm{N}-1} \sum_{\mathrm{j}=\mathrm{i}+1}^{\mathrm{N}} \hat{\rho}_{j i}\right\}$

olarak tanımlanmaktadır. Yatay kesit bağımlılığının yani birimler arası korelasyonun olmadığını ifade eden $\mathrm{H}_{0}$ hipotezi altında $\mathrm{CD} \stackrel{d}{\rightarrow}$ iken $\mathrm{N}(0,1)$ ve T yeterince büyük iken $\mathrm{N} \rightarrow \infty$ gitmektedir. $\mathrm{CD}$ istatistiği homojen / heterojen dahil olmak üzere çok çeşitli panel veri modelleri altında $\mathrm{T}$ ve N'nin sabit değerleri için sıfır olmaktadır (Horos ve Sarafidis,2006:485). Dengeli panel için geliştirilen $\mathrm{CD}$ istatistiğinde yer alan $\hat{\rho}_{j i}$ :

$\hat{\rho}_{i j}: \hat{\rho}_{j i}=\frac{\sum_{t=1}^{T} e_{i t} e_{j t}}{\left\{\sum_{t=1}^{T} e_{i t}^{2}\right\}^{1 / 2}\left\{\sum_{t=1}^{T} e_{j t}^{2}\right\}^{1 / 2}}$

$\mathrm{e}_{\mathrm{i}}$, her birimden tahmin edilen kalıntıları göstermekte iken $\mathrm{T}_{\mathrm{ij}}$ korelasyon katsayısı hesaplanan gözlem sayısıdır. $H_{0}$ hipotezi birimlerarası korelasyon olmadığını ifade etmekte ve $T_{i j}>3$ ve $N$ yeterince büyük olduğu durumda söz konusu istatistik normal dağılıma sahiptir (Tatoğlu Yerdelen,2017:105).

Birimlerarası korelasyonun varlığının sınanması sonrasında serilerin birim köklü olup olmadığının sınanması aşamasına geçilmektedir. Panel analizinde kullanılan bölgesel seriler arasında yatay kesit bağımlılığının tespit edilmesi sonrasında, yatay kesit bağımlılığının söz konusu olduğu durumlarda durağanlığın test edilmesinde ikinci kuşak birim kök testlerinden Pesaran'ın geliştirdiği ve yatay kesit genişletilmiş Dickey Fuller (CADF) olarak adlandırılan birim kök testinden yararlanılmıştır. Pesaran (2007) birim kök testlerini tahmini faktörlerden sapmalara dayandırmak yerine, bireysel serilerin ilk farkları ve gecikmeli değerlerinin yatay kesit ortalamalarını standart DF (veya ADF) regresyonlarına ilave etmektedir (Pesaran,2007:266).

Otokorelasyon olmadığı durumda dinamik lineer heterojen panel veri modeli aşağıdaki şekilde yazılmaktadır.

$Y_{i t}=\left(1-\emptyset_{i}\right) \mu_{i}+\emptyset_{i} Y_{i t-1}+u_{i t}$

$\mathrm{u}_{\mathrm{it}}$ genel bir faktör yapısına sahipken $f_{t}$ gözlenemeyen faktör olarak ifade edilmektedir.

$u_{i t}=\gamma_{i} f_{t}+\varepsilon_{i t}$ 
Otokorelasyon yokken CADF regresyon modeli;

$\Delta Y_{i t}=\alpha_{i}+b_{i} z_{i, t-1}+c_{i} \bar{z}_{t-1}+d_{i} \Delta \bar{z}_{t}+\varepsilon_{i t}$

şeklinde tanımlanmaktadır. Serilerin durağan olup olmadığının sınanmasında kullanılan hipotez ise; $\mathrm{H}_{0}: \beta_{\mathrm{i}}=0$ bütün i'ler için geçerli iken alternatif hipotez $\mathrm{H}_{1}: \beta_{\mathrm{i}}<0, \ldots \ldots \beta_{\mathrm{N} 0}<0, \mathrm{~N}_{0} \leq \mathrm{N}$ bütün panel veri seti için geçerlidir (Cerasa,2008). CADF istatistikleri, IPS $t$-çubuğu testinin değiştirilmiş bir sürümünü geliştirmek için kullanılmaktadır. IPS testinin yatay kesit genişletilmiş şekli olan CIPS istatistiği aşağıdaki şekilde ifade edilmektedir (Barbieri,2006).

$\mathrm{CIPS}=N^{-1} \sum_{\mathrm{i}=1}^{N} C A D F_{i}$

Bu testin dağılımı, asimptotik olarak standart değildir. \%1, \%5 ve \%10 kritik değerler farklı $\mathrm{N}$ ve T kombinasyonları için hesaplanmış ve Pesaran (2007)'de tablolaştırılmıştır. Bireye özgü hata terimlerinin seriye ait korelasyonu durumunda, CADF regresyonunda $\bar{z}_{t}$ ve $\Delta \bar{z}_{t}$ için istatistiksel dağ 1 lımda herhangi bir değişikliğe gitmeden uygun sayıda gecikmeli değer eklenerek test prosedürü genişletilmektedir (Cerasa,2008). Pesaran tarafından geliştirilen CADF ve CIPS testleri yatay kesit bağımlılığının tek bir ortak faktörden kaynaklandığı durumlarda birim kök testi için tasarlanmıştır. Ancak CIPS testi bireysel CADF testlerinden daha güçlü özelliklere sahip olduğundan tercih edilmektedir (Barbieri,2006). Pesaran tarafindan yapılan Monte Carlo simülasyonlarında CADF test istatistiğinin hem $\mathrm{N}>\mathrm{T}$ hem de $\mathrm{T}>\mathrm{N}$ olduğu durumlarda etkin sonuçlar verdiği savunulmaktadır (Dilber \& Sönmez,2016:145).

Serilerde durağanlığın test edilmesinden sonra eşbütünleşme analizine yer verilmektedir. Eşbütünleşme analizi uzun dönemde seriler arasında karşı1lıkı bir ilişkinin bulunup bulunmadığını araştırmak amaciyla uygulanmaktadır. Bu noktada sabit ve eğim parametrelerinin birimlere göre homojen olup olmadıklarının tespiti önem arz etmektedir. Nitekim uygulanacak eş bütünleşme analizi sabit ve eğim parametrelerinin homojenliğine göre değişmektedir. Homojenliğin belirlenmesinde F testi, Swamy testi, G testi ve Delta testi gibi testler kullanılmaktadır. Pesaran ve Yamagata (2008) $\mathrm{N}>\mathrm{T}$ olduğu durumda Delta testinin kullanılmasını önermektedir. Basit eş bütünleşme modelinde;

$Y_{i t}=\alpha+\beta_{i} X_{i t}+\varepsilon_{i t}$

şeklinde ifade edilen denklemde $\beta_{i}$ katsayılarının yatay kesit birimleri arasında homojen olup olmadığı delta testiyle sinanmaktadır. Pesaran ve Yamagata (2008), büyük (8) ve küçük (9) örneklemlerde geçerli olmak üzere 2 adet delta istatistiği geliştirmişlerdir (Topal \& Ünver,2016).

$\widehat{\Delta}=\sqrt{N}\left\{\frac{N^{-1} S-k}{2 k}\right\} \sim x_{k}^{2}$

$\widehat{\Delta} a d j=\sqrt{N}\left\{\frac{N^{-1} S-k}{v(T, k)}\right\} \sim N(0,1)$

Yukarıdaki denklemlerde N, yatay kesit sayısını gösterirken S, Swamy test istatistiğini, k açıklayıcı değişken sayısını ve $\mathrm{v}(\mathrm{T}, \mathrm{k})$ standart hatayı göstermektedir. Delta testine ait hipotezler ise: $H_{0}: \beta_{1}=\beta$ eğim katsayılarının homojen olduğunu, $H_{1}: \beta_{i} \neq \beta$ ise eğim katsayılarının homojen olmadığını ifade etmektedir (Topal \& Ünver,2016).

Seriler arasındaki uzun dönemli ilişkinin tespiti için eşbütünleşme testinin yapılması gerekmektedir. Eşbütünleşme testleri birinci ve ikinci kuşak testler olmak üzere ikiye ayrılmaktadır. Eğer seriler arasında yatay kesit bağımlılı̆̆ı yoksa birinci kuşak eşbütünleşme testleri, yatay kesit bağımlılığ 1 varsa ikinci kuşak panel eş bütünleşme testleri kullanılmaktadır. Çalışmada Gengenbach, Urbain ve Westerlund panel eş bütünleşme testinden yararlanılmıştır. Söz konusu testin seçilmesinde hata düzeltme modeli temeline dayanmasının yanı sıra birimler arası korelasyon ve heterojenliğe önem vermesi etkilidir (Tatoğlu Yerdelen,2017). Testin ilk aşamasında bütün birimlerin ayrı ayrı en 
küçük kareleri tahmin edilmekte ve $H_{0}: \alpha_{y_{i}}=0$ hipotezi $\mathrm{t}$ testi yardımı ile sınanmaktadır. Burada $\mathrm{t}$ istatistiği;

$t_{c_{i}}=t_{\alpha_{y i}}=\frac{\widehat{\alpha}_{y_{i}}}{\widehat{\sigma}_{\widehat{\alpha}_{y_{i}}}}$

şeklinde tanımlanmakta ve panel test istatistiği ise her bir birime özgü test istatistiğinin ortalamasıdır ve

$$
\bar{t}_{c}=\frac{1}{N} \sum_{\dot{\mathrm{I}}=1}^{N} t_{c_{i}}
$$

olarak ifade edilir (Tatoğlu Yerdelen,2017). Gengenbach, Urbain ve Westerlund eşbütünleșme testinin temel hipotezi $H_{0}: \alpha_{y_{i}}=\ldots=\alpha_{y_{N}}=0$ iken alternatif hipotez ise ez az bir i değeri için $H_{1}: \alpha_{y_{i}}<0$ olarak kurulmaktadır (Gengenbach vd.:2009).

Seriler arasında eşbütünleşik ilişkinin varlığının sınanmasının ardından birimler arası korelasyonun varlığında uzun dönemli eşbütünleşme katsayılarının tahmininde heterojen panel veri modelleri için çeşitli yöntemler kullanılmaktadır. Panel zaman serisi analizinde ortalama grup tahmincisi (MG) ve havuzlanmış ortalama grup tahmincisi (PMG) gibi tahminciler heterojenliğe izin vermekte fakat birimlerarası korelasyon karşısında direnç gösterememektedir. Yeni nesil tahminciler olan genişletilmiş ortalama grup (AMG) tahmincisi ve ortak korelasyonlu etkiler (CCE) tahmincileri birimler arası korelasyonu da dikkate almaktadır (Kar ve Kar, 2018:2553). Analizde bu yöntemlerden biri olan genişletilmiş ortalama grup (AMG) tahmincisi kullanılmıştır.

$\mathrm{i}=1, \ldots \ldots \ldots, \mathrm{N}$ ve $\mathrm{t}=, \ldots \ldots \ldots, \mathrm{T}$ iken;

$\mathrm{y}_{\mathrm{it}}=\beta_{\mathrm{i}}^{\prime} \mathrm{x}_{\mathrm{it}}+\mathrm{u}_{\mathrm{it}} \quad \mathrm{u}_{\mathrm{it}}=\alpha_{\mathrm{i}}+\lambda_{\mathrm{i}}^{\prime} \mathrm{f}_{\mathrm{t}}+\varepsilon_{\mathrm{it}}$

$\mathrm{x}_{\mathrm{mit}}=\pi_{\mathrm{mi}}+\delta_{\mathrm{mi}}^{\prime} \mathrm{g}_{\mathrm{mt}}+\mathrm{p} 1_{\mathrm{mi}} \mathrm{f} 1_{\mathrm{mt}}+\ldots+\mathrm{p}_{\mathrm{nmi}} \mathrm{f}_{\mathrm{nmt}}+\mathrm{u}_{\mathrm{mit}}$

$\mathrm{m} 01, \ldots, \mathrm{kvef}_{\text {.mt }} \subset \mathrm{f}_{\mathrm{t}}$

$\mathrm{f}_{\mathrm{t}}=\mathrm{Q}^{\prime} \mathrm{f}_{\mathrm{t}-1}+\epsilon_{\mathrm{t}}$ ve $\mathrm{g}_{\mathrm{t}}=\mathrm{K}^{\prime} \mathrm{g}_{\mathrm{t}-1}+\epsilon_{\mathrm{t}}$

Denklem 12'de $x_{i t}$ gözlemlenebilir ortak değişkenlerin bir vektörüdür. $\alpha_{i}$ gruba özgü sabit etkiler kombinasyonunu, $f_{t}$ bir dizi ortak faktörü ve $\lambda_{i}$ ülkeye özgü faktör yüklemelerini vermektedir. Denklem-13'de gözlemlenemeyen ortak faktörler olan $f_{t}$ ve $g_{t}$ nin doğrusal fonksiyonu olarak modellenen k'nın gözlemlenebilir regresörlerin ampirik gösterimi ülkeye özgü faktör yüklemeleri ile modele eklenmiştir. Kurulan model gözlemlenebilir ve gözlemlenemeyen faktörlerde yatay kesit bağımlılığını göstermektedir. Denklem-12'de $y_{i t}$ varyasyonunu yönlendiren gözlemlenemeyen ortak faktörler aynı zamanda denklem-13'deki regressörleri de yönlendirmektedir. Denklem-13 gözlemlenmeyen faktörlerin oluşumunu belirtmektedir (Eberhardt \& Bond,2009). AMG yönteminde hata düzeltme modeline t-1 gecikmeli zaman gölge değişkeninin ilave edilmesiyle ve değişkenlerin birinci farklarının alınmasıyla tahmin edilmektedir. Daha sonra birimler için ayrı ayrı kurulan hata düzeltme modeline bahsi geçen tahminler eklenmektedir. AMG tahvemin sonuçları tüm birimler bazında ortalama alınmak kaydı ile panelin geneli için elde edilmektedir (Tatoğlu Yerdelen,2017:303)

\section{Araştırma Bulguları}

Ampirik araştırmanın ilk aşamasında paneli oluşturan birimler arasındaki korelasyonun varlığının sınanması için Pesaran CD testinden yararlanılmıştır. Test sonuçlarına dair çıktı Tablo-1' de gösterilmektedir. 
Tablo 1: Birimler Aras1 Korelasyon Testi

\begin{tabular}{llll}
\hline Değişkenler & CD testi & Katsayı & P değeri \\
\hline LKBGSYH-LTET & 56.65 & 0.840 & $0.000^{*}$ \\
\hline
\end{tabular}

* \%1 düzeyinde anlamlılığı ifade etmektedir.

CD birimler arası korelasyon testi sonuçlarına göre birimler arası korelasyonun olmadığını ifade eden $\mathrm{H}_{0}$ hipotezi reddedilmekte ve birimler arasında korelasyonun varlığı doğrulanmaktadır. Korelasyon katsayısı 0.84 'dür.

Birimler arası korelasyonun varlığı analizde uygulanacak birim kök testlerinden ikinci kuşak testlerin kullanımını gerektirmektedir. Çalışmada serilerin durağanlığı yatay kesit genişletilmiş Dickey Fuller (CADF) ile test edilmiştir. Tablo-2'de sabite izin verildiği ve bir gecikmeli CADF test istatistiğinin ortalaması olan ve yatay kesit genişletilmiş Im, Pesaran ve Shin panel birim kök testi olarak adlandırılan (CIPS) testi sonuçları görülmektedir.

Tablo 2: CIPS Birim Kök Testi Sonuçları

\begin{tabular}{lcccccc}
\hline \multicolumn{7}{c}{$\mathrm{I}(0)$ Düzey Değerleri } \\
\hline Değişkenler & $\mathrm{t}$-bar & $\mathrm{cv10}$ & $\mathrm{cv} 5$ & $\mathrm{cv} 1$ & $\mathrm{Z}(\mathrm{t}-\mathrm{bar})$ & P değeri \\
LKBGSYH & -2.024 & -2.070 & -2.170 & -2.340 & -1.408 & $0.080^{* * *}$ \\
LTET & -2.024 & -2.070 & -2.170 & -2.340 & -1.407 & $0.080^{* * *}$ \\
\hline \multicolumn{7}{c}{$\mathrm{I}(1)$ Birinci Fark Değerleri } \\
\hline LKBGSYH & -2.691 & -2.070 & -2.170 & -2.340 & -4.502 & $0.000^{*}$ \\
LTET & -3.303 & -2.070 & -2.170 & -2.340 & -7.338 & $0.000^{*}$ \\
\hline
\end{tabular}

*,*** sirasıyla $\% 1$ ve $\% 10$ düzeyinde anlamlılı̆̆ ifade etmektedir.

Serilerin durağanlığı ilk olarak düzey değerleriyle analiz edilmiştir. Analiz sonuçlarına göre bağımlı ve bağımsız değişken için t-bar (CIPS) istatistiği \%90 (cv10), \%95 (cv5) ve \%99 (cv1) güven aralığında verilen kritik değerlerden mutlak olarak küçüktür. Diğer yandan Z(t-bar) istatistik değerleri de serinin düzeyde durağan olmadığını göstermektedir. Bu noktada serilerin birinci fark1 alınarak birim kök testi yenilenmektedir. Birinci farkı alınmış serilerin t-bar istatistik değerleri \% 090 (cv10), \%95 (cv5) ve \%99 (cv1) güven aralığında mutlak değer olarak verilen kritik değerlerden büyüktür. Birinci farkı alınan serilerin $\mathrm{Z}(\mathrm{t}$-bar) istatistik değerleri de serilerin durağan olduğunu göstermektedir.

Serilerin birinci farkında durağan olduğunun tespit edilmesinin ardından sabit ve eğim parametrelerinin birimlere göre homojen olup olmadıklarının tespiti önem arz etmektedir. Söz konusu homojenliğin tespiti için $\mathrm{N}>\mathrm{T}$ durumunda güvenilir sonuçlar veren delta testi kullanılmıştır. Tablo-3'de delta testi sonuçları görülmektedir.

Tablo 3: Homojenlik Testi (Delta Testi) Sonuçları

\begin{tabular}{l|l|l}
\hline Delta Test & İstatistikler & P değeri \\
\hline$\Delta$ & 2.076 & $0.038^{* *}$ \\
$\Delta_{a d j}$ & 2.342 & $0.019^{* *}$ \\
\hline
\end{tabular}

**, \%5 düzeyinde anlamlılığ 1 ifade etmektedir. 
Delta testi ve düzeltilmiş delta testi sonuçlarına göre sabit ve eğim parametrelerinin homojen olduğunu ifade eden $\mathrm{H}_{0}$ hipotezi reddedilmiştir ve parametreler heterojendir. Seriler arasında eşbütünleşme olup olmadığının sınanma yöntemi ise sabit ve eğim parametrelerinin homojenlik testi sonuçlarına göre değişmektedir. Heterojenlik durumunda ikinci kuşak panel eşbütünleşme testlerinden Gengenbach Urbain ve Westerlund testi kullanılmış ve sonuçlar Tablo-4'de gösterilmiştir.

Tablo 4: Panel Eşbütünleşme Testi Sonuçları

\begin{tabular}{llll}
\hline d.y & Katsayı & T istatistiği & P değeri \\
y(t-1) & $-1.054^{*}$ & -2.809 & $<0.01$ \\
\hline \multicolumn{2}{l}{ Uzun Dönemli İlişkinin Tahmini:Ortalama Grup En Küçük Kareler (DOLSMG) Tahmincisi } \\
\hline LKBGSYH & Beta Katsayısı & T istatistiği & \\
LTET & 0.139 & 5.262 & \\
\hline
\end{tabular}

*, \%1 düzeyinde anlamlılı̆ı ifade etmektedir.

Tablo-4'de verilen sonuçlara göre panel eşbütünleşme testi için bağımlı değişkenin gecikmeli değeri olan $\mathrm{y}(\mathrm{t}-1)$ 'in anlamlılı̆g incelendiğinde $(\mathrm{p}$ değeri $<0.01)$ olduğundan $\mathrm{H}_{0}$ hipotezi reddedilmektedir. Dolayısıyla LKBGSYH bağımlı değişkeni ile LTET bağımsız değişkeni arasında eşbütünleşme ilişkisinin varlığı kabul edilmektedir. Beta katsayısı uzun dönem parametre tahminini göstermektedir. Diğer yandan uzun dönem t istatistiği anlamlıdır. DOLSMG sonuçlarına göre uzun dönemde LTET bağımsız değişkeni LKBGSYH bağımlı değişkenini etkilemektedir. Toplam elektrik tüketiminin yüzdesel değişiminde meydana gelen 1 puanlık artış kişi başı GSYH'da meydana gelen yüzdelik değişimi 0.14 puan arttırmaktadır. Ekonometrik araştırmanın son kısmında birimlerarası korelasyonun ve heterojenliğin varlığında eşbütünleşme katsayılarının tahmini için geliştirilen panel genişletilmiş ortalama grup (AMG) tahmincisinden yararlanılmıştır. Tahmin sonuçları Tablo-5'de verilmektedir.

Tablo 5: Eşbütünleşme Katsayıları Tahmini

\begin{tabular}{llll}
\hline LKBGSYH & Katsayı & T istatistiği & P değeri \\
\hline LTET & 0.275 & 4.04 & $0.000^{*}$ \\
\hline & Eşbütünleşme Testine Dair Diğer İstatistikler & \\
\hline Hata düzeltme parametresi & -1.84 & -50.56 & $0.000^{*}$ \\
Wald test istatistiği & & 9375.03 & \\
Wald p değeri & & $0.000^{*}$ \\
\hline
\end{tabular}

*, \%1 düzeyinde anlamlılı̆̆ ifade etmektedir.

Tablo-5'de panelin geneli için AMG tahmincisi kullanılarak hata düzeltme modelinin tahmini yer almaktadır. Sonuçlara bakıldığında bu bölgelerde elektrik tüketiminde meydana gelen artış, kişi başı gayri safi yurtiçi hasılayı pozitif ve istatistiksel olarak anlamlı düzeyde etkilemektedir. Modelde hata düzeltme katsayıs1 -1.84'dir. Hata düzeltme katsayıs $\% 1$ düzeyinde istatistiksel olarak anlamlıdır. Bu yaklaşıma göre ortaya çıkacak beklenmeyen bir kısa dönem şok etkisi, uzun dönemde her yıl \%1.84 oranında düzeltilerek dengeye gelineceğini belirtmektedir. Bu durum, uzun dönemde eşbütünleşme ilişkisi içinde olan serilerde kısa dönemde meydana gelen sapmaların giderildiği ve serilerin uzun dönemde yeniden denge değerine yaklaştıkları şeklinde ifade edilebilir. Diğer yandan serilerin eşbütünleşik olması serilerle yapılacak uzun dönem analiz sonuçlarının güvenilir olacağını da göstermektedir. 


\section{Sonuç}

Enerji, günümüz ekonomilerinin büyüme ve kalkınma çabalarının gerçekleştirilmesinde önemli bir rol oynamaktadır. Teknolojinin ilerlemesi ve dünya nüfusundaki artışa bağlı olarak küresel toplam talebin artması üretimi teşvik etmekte ve nihayetinde enerji ihtiyacını arttırmaktadır. $\mathrm{Bu}$ bağlamda kullanım kolaylığı sağlaması, çevre dostu yapısı ve hızlı erişimi dolayısı ile elektrik enerjisi enerji kaynakları arasında sıklıkla tercih edilmektedir. Ayrıca ekonomik gelişmişlik düzeyinin yanısıra toplumsal gelişmişlik düzeyinin belirlenmesinde de elektrik tüketiminin etkisi büyüktür.

$\mathrm{Bu}$ çalı̧̧mada elektrik tüketiminin ekonomik büyüme üzerindeki etkisi Türkiye özelinde İBBS (istiatistiki bölge birimleri sınıflandırması) çerçevesinde düzey-2 bölgeleri olarak adlandırılan 26 alt bölge, 2005-2018 yılları arası dönem için panel veri yöntemi ile analiz edilmiştir. Analiz sonucunda elektrik tüketimi ve ekonomin büyüme arasında uzun dönemli ilişkinin varlığı tespit edilmiştir. Söz konusu ilişki elektrik tüketiminde meydana gelen değişmenin ekonomik büyüme üzerinde etkisi olduğunu ifade etmektedir. Elektrik tüketiminin ekonomik büyüme üzerindeki uzun vadeli pozitif etkisi, elektrik tüketimine yönelik belirlenecek politikaların önemini arttırmaktadır.

Türkiye'nin enerjide dışa bağımlı olması ve özellikle elektrik enerjisi açığının ithal doğalgaz ile karşılanmaya çalışılması enerji maliyetlerini arttırmaktadır. Her ne kadar maliyet artışları elektrik tüketiminde kısıntıya gidilmesini gündeme getirecek olsa da büyüme üzerinde önemli bir etkisi olan elektrik tüketiminde kısıntıya gidilmesi sosyoekonomik açıdan olumsuz etkiler oluşturacaktır. $\mathrm{Bu}$ kapsamda elektrik tüketimine yönelik politikaların kaynak israfını önleyecek şekilde yeniden dizayn edilmesi büyük önem taşımaktadır. Elektrik nakil sürecinde ortaya çıkacak kayıpların ve kaçak kullanımın önlenmesi adına alınacak ilave tedbirlerin ivedi şekilde uygulamaya konulması gerekmektedir.

Elektrik enerjisinin birincil enerji olarak adlandırılan fosil kaynaklardan elde ediliyor olmas1 aynı zamanda elektrik enerjisi arzının yenilenemez kaynaklara bağımlı olduğunu gözler önüne sermektedir. Elektrik enerjisi temininde yenilenemez kaynaklara olan bağımlılığın azaltılması için alternatif enerji sistemlerinin geliştirilmesi elzemdir. Türkiye'nin içinde bulunduğu coğrafi şartlar ve iklim özellikleri, yenilenebilir enerji kaynakları olan güneş, dalga ve rüzgar gücünden elektrik enerjisi üretilmesine imkan sağlamaktadır. Bu nedenle kamu ve özel sektör bünyesinde yenilenebilir enerji yatırımlarının teşviki elektrik enerjisi üretiminde büyük rol oynamakta ve özellikle yerli üretim teknolojilerinin geliştirilmesi için politik adımların atılması önem arz etmektedir.

\section{Kaynakça}

Adeniyi, O. \& A.O. Adewuyi (2019). Energy consumption and sectoral trade in selected West African economies, International Journal of Global Energy Issues, 42(1), 81-125 https://doi.org/10.1504/IJGEI.2019.100691

Adhikari, D. \& Chen, Y. (2012). Energy consumption and economic growth: a panel cointegration analysis for developing countries, Review of Economics \& Finance, 3, 68-80.

Atif, S. Y. \& Siddiqi, M. W. (2010). The electricity consumption and economic growth nexus in Pakistan: a new evidence, EconStor Preprints 65688, ZBW - Leibniz Information Centre for Economics., http://dx.doi.org/10.2139/ssrn.1569580

Aydın, B. \& Bozdağ, A. (2018). Elektrik tüketimi ve ekonomik büyüme arasındaki ilişki: Avrupa Birliği ve Türkiye örneği, International Journal of Academic Value Studies, 4(18), 7080. https://doi.org/10.23929/javs.702 
Bah, M. M., \& Azam, M. (2017). Investigating the relationship between electricity consumption and economic growth: evidence from South Africa, Renewable and Sustainable Energy Reviews, 81, 531-537. https://doi.org/10.1016/j.rser.2017.05.251

Barbieri, L. (2006). Panel unit root tests: a review, Serie Rossa: Economia - Quaderno, 43.

Cerasa, A. (2008). CIPS test for unit root in panel data: further monte carlo results. Economics Bulletin, 3(16), 1-13.

Cowan, W. N., Chang, T., Inglesi-Lotz, R. \& Gupta, R. (2014). The nexus of electricity consumption, economic growth and CO2 emissions in the BRICS countries, Energy Policy, 66, 359-368. https://doi.org/10.1016/j.enpol.2013.10.081

Das, A. \& Mcfarlane, A. (2019). Non-linear dynamics of electric power losses, electricity consumption, and gdp in Jamaica, Energy Economics, 84, 1-10. https://doi.org/10.1108/JES02-2013-0022

Dilber, İ. \& Sönmez, F.E. (2016). Thirlwall kanununun gelişmiş ülkeler açısından geçerliliği: panel veri analizi, Uluslararası Alanya İsletme Fakültesi Dergisi, 8(2), 139-150.

Dudzevičıūtè, G. \& Šimelytė, A. (2017). Export, energy consumption and economic growth interlinkages: the case of Lithuania, Scientific Annals of Economics and Business, 64(3), 395410.

Eberhardt, M. \& Bond, S. (2009), Cross-section dependence in nonstationary panel models: a novel estimator, MPRA, Paper No. 17870.

Enerdata, (2019). Global energy highlights 2019 edition, erişim:15.06.2020 https://yearbook.enerdata.net/highlights/\#introduction,

Ergün, S. \& Atay Polat, M. (2015). OECD ülkelerinde co2 emisyonu, elektrik tüketimi ve büyüme ilişkisi, Erciyes Üniversitesi İktisadi ve İdari Bilimler Fakültesi Dergisi, 45: 115-141. https://doi.org/10.18070/euiibfd.89737

Faisal, Tursoy, T. \& Reşatoğlu, N.G. (2016). Energy consumption, electricity, and gdp causality; the case of Russia, 1990-2011, Procedia Economics and Finance, 39, 653-659. https://doi.org/10.1016/S2212-5671(16)30312-4

Ferguson, R., Wilkinson, W. \& Hill, R., (2000). Electricity use and economic development, Energy Policy 28, 923-934. https://doi.org/10.1016/S0301-4215(00)00081-1

Gengenbach, C., Urbain, J.-P., \& Westerlund, J. (2009). Panel error correction testing with global stochastic trends (updated version of research memorandum 2008- 051). Maastricht: METEOR, Maastricht Research School of Economics of Technology and Organization

Ghosh, S. (2002). Electricity consumption and economic growth in India, Energy Policy, 30, 125129. https://doi.org/10.1016/S0301-4215(01)00078-7

Güvenoğlu, H. \& Aydın, C. (2018). Elektrik tüketiminin ekonomik büyüme üzerindeki etkisi: il bazında Türkiye örneği (2007-2014), II. International Symposium on Economics, Finance and Econometrics, 6-7 December, Bandirma.

Hirsh, R. F. \& Koomey, J.G. (2015). Electricity consumption and economic growth: a new relationship with significant consequences?, The Electricity Journal, 28(9), 72-84. https://doi.org/10.1016/j.tej.2015.10.002

Horos, R. E. \& Sarafidis, V. (2006). Testing for cross-sectional dependence in panel-data models, The Stata Journal, 6(4), 482-496. https://doi.org/10.1177/1536867X0600600403 
Ikegami, M. \& Wang, Z. (2016). The long-run causal relationship between electricity consumption and real gdp: evidence from Japan and Germany, Journal of Policy Modeling, 38(5), 767784.

IEA, (2019). World Energy Outlook, erişim: 16.06.2020 https://www.iea.org/reports/world-energyoutlook-2019/electricity\#abstract

Kar, M. \& Kar, B.B. (2018). Mobil arabağlant1 ücret düzenlemelerinde su yatağ1 etkisi: Türkiye örneği, Social Sciences Studies Journal, 4(20), 2543-2557. https://doi.org/10.26449/sssj.659

Karagöl, E., T. \& Tür, M. R. (2017). Türkiye'de elektrik enerjisi, SETA Yayınları, No:96.

Kraft, J. \& Kraft, A. (1978). On the relationship between energy and GNP, The Journal of Energy and Development, 3(2), 401-403.

Osman, M.; Gachino, G. \& Hoque, A. (2016). Electricity consumption and economic growth in the GCC countries: panel data analysis, Energy Policy, 98: 318-327. https://doi.org/10.1016/j.enpol.2016.07.050

Overgaard, S. (2008). Definition of primary and secondary energy, erişim: 15.06.2020 https://unstats.un.org/unsd/envaccounting/londongroup/meeting13/LG13_12a.pdf,

Öz, S. \& Tohay, S. (2018). Elektrik sektöründeki yapısal reformların ekonomik büyüme üzerindeki etkileri: Türkiye örneği, Maliye Araştırmaları Dergisi, 4(3), 171-184.

Özaslan, M. (2015). Türkiye'de ekonomik ve sosyal boyutlarıyla bölgesel gelişmişlik farklılıkları, erişim:

10.06.2020 http://tucaum.ankara.edu.tr/wpcontent/uploads/sites/280/2015/08/semp4_17.pdf.

Pata, U.K. \& Yurtkuran, S. (2017). The Relationship between electricity consumption and economic growth in the selected member countries of the international energy agency (IEA): an ardl bounds test approach, Iran. Econ. Rev. 21(2), 341-364.

Pesaran, H.M. (2007). A Simple panel unit root test in the presence of cross-section dependence, Journal of Applied Econometrics, 22, 265-312. https://doi.org/10.1002/jae.951

Pesaran, M. ve Yamagata, T. (2008). Testing slope homogeneity in large panels, Journal of Econometrics, 142(1), 50-93.

Shengfeng, X., Sheng, X.M., Tianxing, S.Z. \& Xuelli, Z. (2012). The relationship between electricity consumption and economic growth in China, Physics Procedia, 24, 56-62 https://doi.org/10.1016/j.phpro.2012.02.010

Tang, C.F. (2008). A re-examination of the relationship between electricity consumption and economic growth in Malaysia, Energy Policy, 36(8), 3077-3085. https://doi.org/10.1016/j.enpol.2008.04.026

Tang, C. F., Tan, B. W. Ve Ozturk, I. (2016). Energy consumption and economic growth in Vietnam. Renewable and Sustainable Energy Reviews, 54, 1506-1514. https://doi.org/10.1016/j.rser.2015.10.083

Tatoğlu Yerdelen, F. (2013). Ileri Panel Veri Analizi Stata Uygulamalı, 2. Baskı, Beta

Tatoğlu Yerdelen, F. (2017). Panel zaman serileri analizi: stata uygulamal, Beta

Türkmen, S., Özbek, S. \& Karakuş, M. (2018). Türkiye'de elektrik tüketimi ve ekonomik büyüme arasındaki ilişki: ampirik bir analiz, Kahramanmaraş Sütçü Imam Üniversitesi İktisadi ve İdari Bilimler Fakültesi Dergisi, 8(2), 129-142. 
Quang, C, L. (2011). Electricity consumption and economic growth in Vietnam: a cointegration and causality analysis. Journal of Economics and Development, 13(3), 24-36.

Yaprakl1, S. \& Yurttançıkmaz, Z.Ç. (2012). Elektrik tüketimi ile ekonomik büyüme arasındaki nedensellik: Türkiye üzerine ekonometrik bir analiz, C.Ü. İktisadi ve İdari Bilimler Dergisi, 13(2), 195-215.

Yıldırım, C., \& Dağdemir, Ö. (2018). Türkiye'de ekonomik büyüme ve elektrik tüketimi ilişkisi, Sakarya İktisat Dergisi, 7(4), 57-76.

Yoo, S. H. (2006), The causal relationship between electricity consumption and economic growth in the ASEAN countries, Energ Policy, 34(18), 3573-3582. https://doi.org/10.1016/j.enpol.2005.07.011

Yoo, S.H. \& Kwak, S.Y. (2010). Electricity consumption and economic growth in seven South American countries, Energy Policy, 38, 181-188. https://doi.org/10.1016/j.enpol.2009.09.003 